\title{
The Effects of a DLSCL Approach on Students Conceptual Understanding in an Undergraduate Introductory Physics Lab
}

\author{
Muhammad Riaz ${ }^{1,2^{*}}$, Thomas J. Marcinkowski ${ }^{3}$, Ali Faisal ${ }^{4}$ \\ ${ }^{1}$ Assistant Professor, Department of Physics, Karakorum International University Gilgit. PAKISTAN \\ 2 Department of Mathematics Education, Florida Institute of Technology, Melbourne, Florida, USA \\ ${ }^{3}$ Professor and Program Chair, Department of Mathematics Education, Florida Institute of Technology, Melbourne, Florida, USA \\ ${ }^{4}$ Office of Development, Florida Institute of Technology, Melbourne, Florida, USA
}

Received 20 June 2019 - Revised 12 September 2019 • Accepted 12 September 2019

\begin{abstract}
This study investigated the effects of Discovery Learning Scientific Community Laboratories (DL-SCL) and traditional non-DLSCL laboratories on students' conceptual understanding in a Physics-1 lab. At many universities, physics programs use a traditional lab style, despite research on the benefits for reform-oriented physics labs. This DL-SCL approach included features of inquiry-based learning (e.g., students generated hypotheses and designed experiments) and scientific community labs (e.g., students discussed designs and findings). This study used a quasi-experimental design with quantitative-method data collection and analysis procedures. Twelve sections of a Physics I lab were assigned to two groups: Treatment (DL-SCL) and Control (non-DL$\mathrm{SCL}$ ). In Treatment and Control sections, conceptual understanding was measured pre/post using the Mechanics Baseline Test (MBT) and the Force Concept Inventory (FCl). Study findings indicated that DL-SCL approach in teaching Physics Lab-1 significantly improved students' conceptual understanding.
\end{abstract}

Keywords: conceptual understanding, discovery learning, force concept inventory, mechanics base line test, physics lab, scientific community labs

\section{INTRODUCTION}

In many colleges, the introductory physics course acts to serve as a gatekeeper function for careers in physics and engineering, as well as other STEM fields. According to the National Research Council (NRC, 2013), it is important to notice that one in every 500 students in introductory physics is eventually enrolled in a graduate program in physics. Student with poor conceptual understanding who do not earn good grades on the final exam find their introductory physics course to be challenging (Seymour \& Hewitt, 1997). Poor conceptual understanding can contribute to poor performance in the course which, in turn, can discourage students from further study in physics and/or other scientific and technical fields (Ivie \& Ray, 2005).

Discovery Learning Scientific Community Laboratories (DL-SCL) are undergraduate physics laboratories where students adopt multiple roles (Bodner, Hunter, \& Lamba, 1998), including ways of utilizing learning strategies and lab resources to build a solid understanding of scientific concepts and of their applications in real life (Sokoloff, Laws \& Thornton, 2007). In this study, DL-SCL labs were designed to be more inquiry-oriented by including pre-lab assignments designed to help prepare students to develop their own hypotheses and then design experiments to test them. In this way, they reflected Piaget's ideas about individual discovery and constructivism. These labs also were designed to be more collaborative and community-based by allowing, even encouraging, students to discuss their hypotheses, designs, and findings with lab teaching assistants (TAs) and other students, both prior to and after each lab. In this way, they also reflected Vygotsky's ideas about social constructivism, including the role of More Knowledgeable Others (MKOs) in supporting learning. Finally, these labs reflected Bandura's ideas about learning from models and about the influence of experiences of mastery (e.g., lab successes) on self-efficacy.

(c) 2020 by the authors; licensee Modestum Ltd., UK. This article is an open access article distributed under the terms and conditions of the Creative Commons Attribution License (http://creativecommons.org/licenses/by/4.0/).

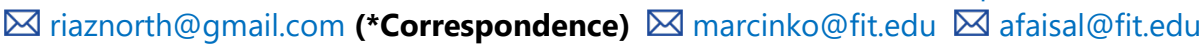




\section{Contribution of this paper to the literature}

- This study provides the effectiveness of Discovery Learning Scientific Community Laboratories (DL-SCL) as compare to Traditional Laboratories - based on students' conceptual understanding. It has transformed traditional content into discovery based learning curriculum by including pre-lab preparation activities pre-lab quizzes, readings, and short-video tutorials - before coming to lab. In DL-SCL students were given free access to all available learning facilities: including technological tools for data collection and analysis, in-lab discussions, and group presentations.

- The students who engaged in all these DL-SCL activities performed better on all in lab experiments, when compared to students who just came to the lab with minimum preparation and performed their experiments. The study indicates that the students exposed to the DL-SCL approach scored higher on measures of conceptual understanding and learning gain.

In this study, the dependent variable, conceptual gain, was measured by both the Mechanics Baseline Test (MBT) (Hestenes \& Wells, 1992) and Force Concept Inventory (FCI) (Hestenes, Wells, \& Swackhamer, 1992). The MBT served as the primary measure of conceptual gain because the MBT was administered by the primary investigator just before and just after the DL-SCL treatment. In contrast, the FCI served as a secondary measure of conceptual gain because the FCI pretest was administered by the Department of Physics and Space Science (PSS) at this university on the first and last day of class in the semester. In this study, scores on the FCI were used to equate the groups on the pretest, and to compare them on the posttest (i.e., about four weeks after completion of the treatment).

\section{BACKGROUND}

According to Docktor and Mestre (2014), an abundance of instructional approaches and accompanying curricular materials have been developed for teaching physics. These instructional reforms involve comprehensive structural changes such as combining lecture, recitation, and labs into a single class environment. Each of these reforms has served as the focus of studies that evaluated the effectiveness of instructional approaches and materials for teaching physics (e.g., by changing overall structure of the class and general curriculum materials such as textbooks and simulations). Of these, approaches related to laboratory teaching methods emphasize making labs more interactive by engaging students in class discussion, revising materials such that students must plan and make decisions, probing for students' understanding during class, and overall success in the course (Redish, 2003).

The introduction of technological tools for collecting and analyzing lab data has transformed physics laboratories; for example, RealTime Physics (Sokoloff, 2012) and video analysis software (Beichner, 1996). Studies of the RealTime Physics laboratories have reported improved student learning in dynamics (Thornton \& Sokoloff, 1997). The University of Minnesota addressed common student preconceptions in RealTime Physics Active Learning Laboratories (Sokoloff, 2012; Sokoloff, Thornton, \& Laws, 2011) and computer-based problem solving labs written in LabVIEW (McCullough, 2000). Using video analysis software (Beichner, 1996) to collect and analyze data that resulted from the motion of objects was perceived to be useful by students and improved their comfort with using computers (Escalada, 1995).

Other approaches and studies have focused on the development of scientific thinking and abilities, such as the Investigative Science Learning Environment (ISLE) (Etkina \& Van Heuvelen, 2007; Etkina et al., 2010), Computerbased Problem-Solving Labs (McCullough, 2000), Microcomputer-based Laboratories (MBL) (Thornton \& Sokoloff, 1990), and Scientific Community Labs (Kung, 2005). The ISLE labs (Etkina et al., 2010) emphasized the development of scientific abilities such as: the ability to interpret and reconstruct information presented in multiple forms (e.g., prose and graphic), design an experiment, collect and analyze data, evaluate an experimental outcome, and communicate in a scientist-like manner. Studies also have found that MBLs improved students' understanding of kinematic concepts and graphs in comparison to paper-and-pencil based activities (Thornton \& Sokoloff, 1990). The Scientific Community Labs developed at the University of Maryland (Lippmann, 2003) used a conceptual approach to learning measurement techniques, including the concept of uncertainty. During lab, students are given openended questions and they must devise an experiment as well as collect and analyze data. Students using this reformed laboratory scored higher on a physical measurement questionnaire and demonstrated better conceptual understanding when comparing data sets. All of these instructional approaches and materials have incorporated elements of constructivist theory by reforming the more traditional and more passive lecture-based teaching approaches to a more student-centered and active approach. This newer approach is collectively referred to as interactive engagement methods (Hake, 1998). 


\section{RESEARCH PROBLEM}

On the one hand, many physics departments continue to rely upon a traditional style of teaching physics laboratories (Docktor \& Mestre, 2014). On the other hand, the literature indicates that substantial reforms have been carried out in physics education, including those related to the development and evaluation of instructional strategies and curriculum (i.e., particularly "interactive engagement methods"), the design and analysis of concept inventories, and the assessment of students' difficulties in learning physics concepts and solving problems. A number of universities have adopted or adapted reforms that involve an interactive exploratory-based learning style in large enrollment classes, including the Technology Enabled Active Learning (TEAL) project at MIT (Dori \& Belcher, 2005), the Physics Program at the University of California at Davis (Upton, 2010), and SCALE-UP at North Carolina State University (Beichner et al., 2007; Saul \& Beichner, 2001). All of these were structured to focus on large-enrollment lecture classes combined with recitations and laboratory sections.

Despite attempts at reform such as these, some reform-oriented physics laboratory programs such as RealTime Physics (Sokoloff, Laws, \& Thornton, 2007), video analysis software (Beichner, 1996), Investigative Science Learning Environment (Etkina \& Van Heuvelen, 2007), and Computer-Based Problem-Solving Labs (McCullough, 2000) have introduced more technological instrumentation, while focusing less on traditional content. Even in Scientific Community Laboratories, purposeful discussions were rare (Gresser, 2006). Students can spend much of their time reading through the lab manual, and little time on sense making as part of their work on conclusive discussions (Gresser, 2006). Thus, it appears that there is room in both traditional and reform-oriented physics laboratory programs for greater attention to traditional physics content. Interactive engagement methods that do so have great potential, particularly when that content is approached using discovery-based instructional strategies for guiding students to acquire scientific conceptions.

\section{SIGNIFICANCE}

Much of the early research on physics laboratories focused on the integration of computer-based instruction and technological tools into the laboratory. However, with the exception of Investigative Science Learning Environment (ISLE), RealTime Physics, and integrated course structures (workshop, studio, SCALE-UP, and TEAL), there has been limited research on the effectiveness of new laboratory approaches and curricula, particularly on conceptual learning.

Within the study setting, the physics laboratories in use at this university (e.g., PHY 2091) have tended to reflect a more traditional style, so there was a need and opportunity to explore how reform-oriented physics laboratory approaches could work here. Further, given the mixed results apparent in the literature, the introduction of reforms in the physics laboratories at this university serves as an opportunity to further investigate their effects on students' conceptual learning.

\section{RESEARCH PURPOSE, QUESTIONS}

The purpose of this study is to compare two different instructional approaches -Discovery Learning Scientific Community Laboratories (DL-SCL; experimental) and non-DLSCL laboratories (control) - based on students' conceptual understanding.

\section{Research Questions}

The main research questions for this research study are given as below.

1. What differences, if any, exist among PHY 2091 students exposed to the treatment and the control group for scores on the Force Concept Inventory (FCI), which was administered to all sections of PHY 2091 by the Department prior to the first Experiment (pre) and after the last Experiment (post)?

2. What is the difference between the treatment and control group membership and students' conceptual understanding, as measured by the Mechanics Baseline Test (MBT)?

\section{RESEARCH DESIGN AND METHODOLOGY}

A quasi-experimental study design, with quantitative-method data collection and analysis procedures, was used to conduct this study in the Physics Department, at a private, independent, scientific and technological university. The accessible population included all students who were registered for Physics Lab 1 (PHY 2091) in Fall 2016. The twelve sections of this Physics I lab were assigned to three groups: Treatment (5 sections); Control (non-DL-SCL with data collection: four sections); and Traditional (non-DL-SCL with limited data collection: 3 
sections). Control group completed all measures while the remaining sections in the Traditional group didn't complete any study measure. Students in Traditional group did not participate in this study.

In this study, teaching assistants (TAs) were responsible for lab instruction. It was possible that differences in TA characteristics and teaching ability could influence the results of this study. In addition, it turned out that one TA was different from the other TAs in his instruction and assessment style. For this reason, he was assigned to lab sections in the Traditional group which was not part of actual experiment (i.e., the Traditional group was used for demographic descriptive and initial group comparison purposes and didn't complete any other study instruments).

The DL-SCL approach was used in five labs (Weeks 5-10), three of which were modified versions of traditional labs and two of which were new labs designed for this study. The control approach included the same modified sequence of eleven labs used in the DL-SCL approach, although the five labs unique to the DL-SCL approach were conducted using the more traditional physics laboratory approach. In summary, in the Treatment (DL-SCL) and Control groups, students completed all eleven labs in the same sequence and completed all study measures, but each group was exposed to a different instructional approach in the five labs unique to the DL-SCL approach.

The Treatment group was organized so as to give students free access to all available learning facilities. Students in this group were given the opportunity to do pre-lab preparation activities - pre-lab quizzes, readings, and video lectures - before coming to lab. This was designed to ensure optimal pre-lab collaborative and engaged learning in an informal setting, while allowing immediate feedback from and support by instructors. Lab instructors (TAs) for treatment and control sections were trained and informed about the research study one week before the semester started. During Weeks 5-10, TAs for treatment group sections implemented this teaching strategy in their labs while working closely with the primary investigator. In the Control group sections, TAs followed the traditional teaching approach. The researcher collected treatment verification data from all sections in the Treatment and Control group on a weekly basis, which allowed him to monitor the fidelity of treatment and the avoidance of multiple treatment interference.

For data collection purposes, student demographic surveys were conducted in both groups within the first month of the study. The FCI was administered at the beginning and end of the semester, while the MTB was administered before Week 5 and after Week 10.

The average normalized gain $(\mathrm{g})$, to compare pre- and post-test scores, was computed by taking the difference of the average percentage of pre and post-test scores and dividing this number by the maximum gain, or 100 percent of the average pretest score (Hake, 1998). This is a common practice in physics education, as reported by Hake (1998) is used to compares the normalized gain for treatment and control groups.

\section{STUDY DELIMITATIONS AND LIMITATIONS}

This study was conducted in the Physics Department, at a private scientific and technical university whose student population is more diverse than at other universities. In addition to that, the study was conducted in physics introductory laboratory only for one Fall semester and not included of physics lecture classes. Twelve sections of this course were taught in Fall 2016. Of these, a total of nine sections were included in this study: five sections were assigned to the Treatment group $(n=74)$, and four to the Control group $(n=62)$. To reduce the potential for multiple treatment interference as an internal validity threat, all control group sections met on Tuesdays and Wednesdays, while all treatment group sections met after that on Wednesdays, Thursdays, and Fridays. In addition, each TA was responsible for one Control group and at least one Treatment group section. The three sections assigned to the Traditional group met later on Mondays, Wednesdays, and Fridays, and served as a second control group $(n=36)$, but with limited involvement in data collection (i.e., the FCI, but not the MBT). This had allowed to minimize experimenter effects by excluding Traditional group from this study. The Traditional group TA was different in his ability and in his competency as compared to the rest of all TAs participated in the study. Moreover, to minimize the initial differences, the researcher compared students' achievements (lab scores on experiments) prior to the treatment, and scores on common lab experiments following the treatment in all three groups. The pretests of FCI and MBT provided baseline data about students enrolled in all sections in Treatment and Control groups.

The sample was diverse, including 36\% of students from Florida, $29 \%$ from other states in the U.S., and 35\% from other countries (China, Oman, Canada, Qatar, France, Libya, Morocco, Brazil, Venezuela, Switzerland, Pakistan, Thailand, Trinidad, Lima Peru, Trinidad, Kenya, Ghana, India, Maine, Singapore, Saudi Arabia, and Germany). Maximum details on students' demographics were documented to facilitate generalizability. After the course began, transferring to other lab sections was discouraged. As a result, experimental mortality was limited, primarily a result of absences and invalid responses. On the FCI, 79.7\% of students in the Treatment group provided valid responses on both the pre- and post-test, while $82.3 \%$ of students in the Control group did so. On the MBT, $91.9 \%$ of students in the Treatment group, and $85.5 \%$ of students in the Control group did so. FCI was administered on the first and last day of class. The MBT pretest was conducted five weeks after the semester started and posttest 
Table 1. ANOVA Results for FCl Pretest and Posttest Comparisons Between the Groups

\begin{tabular}{|c|c|c|c|c|c|}
\hline \multicolumn{6}{|c|}{ A. ANOVA Table for $\mathrm{FCl}$ pretest scores $(n=174)$} \\
\hline Source & DF & Sum of Squares & Mean Square & $F$ Ratio & $p$-value \\
\hline Group & 2 & 601.251 & 300.625 & 0.912 & 0.403 \\
\hline Error & 171 & 56356.928 & 329.573 & & \\
\hline C. Total & 173 & 56958.179 & & & \\
\hline \multicolumn{6}{|c|}{ B. ANOVA Table for $\mathrm{FCl}$ posttest scores $(n=174)$} \\
\hline Source & DF & Sum of Squares & Mean Square & $F$ Ratio & $p$-value \\
\hline Group & 2 & 487.900 & 243.950 & 0.539 & 0.584 \\
\hline Error & 171 & 77328.049 & 452.211 & & \\
\hline C. Total & 173 & 77815.949 & & & \\
\hline
\end{tabular}

Note. $p<0.016$

Table 2. T-Test Comparison of Treatment and Control Group Normalized Gain, Pretest, and Posttest Scores on the MBT

\begin{tabular}{|c|c|c|c|c|c|c|c|}
\hline \multicolumn{8}{|c|}{ A. $t$-test for normalize pre to post gain between $T R$ and CT } \\
\hline Grp & $\mathbf{N}$ & Mean & Std Error & Lower $95 \%$ & Upper $95 \%$ & $t$-Ratio & $p$-value \\
\hline CT & 58 & 0.0259 & 0.018 & -0.010 & 0.061 & 5.055 & $0.0001^{*}$ \\
\hline TR & 73 & 0.1461 & 0.016 & 0.114 & 0.178 & & \\
\hline \multicolumn{8}{|c|}{ B. t-test statistic for MBT pretest scores between TR and CT } \\
\hline Grp & $\mathbf{N}$ & Mean & Std Error & Lower $95 \%$ & Upper $95 \%$ & $t$-Ratio & $p$-value \\
\hline $\mathrm{CT}$ & 57 & 36.918 & 2.122 & 32.718 & 41.118 & -0.791 & 0.431 \\
\hline TR & 72 & 34.671 & 1.889 & 30.934 & 38.408 & & \\
\hline \multicolumn{8}{|c|}{ C. t-test statistic for MBT posttest scores between TR and CT } \\
\hline Grp & $\mathbf{N}$ & Mean & Std Error & Lower $95 \%$ & Upper $95 \%$ & $t$-Ratio & $p$-value \\
\hline CT & 57 & 39.6329 & 2.2133 & 35.253 & 44.013 & 2.071 & $0.04^{*}$ \\
\hline TR & 70 & 45.8071 & 1.9972 & 41.854 & 49.760 & & \\
\hline
\end{tabular}

Note. ${ }^{*} p<0.05$. Grp $=$ groups. $\mathrm{CT}=$ Control group. $\mathrm{TR}=$ Treatment group

four weeks before the semester end. Post hoc power analyses for valid, matching pre/post responses on the FCI from students in all three groups $(n=141)$ was 0.99 , and on the MBT from students in the two groups $(n=121)$ was 0.85 .

\section{RESULTS}

Research question one investigated the equivalence of the Treatment and Control group scores on the FCI (pretest and posttest). The Cronbach's alpha value for FCI pre-test scores was 0.85 , and for FCI post-test scores was 0.84 , indicating that these data were reliable. The results indicated that there were no significant differences among these groups on either the FCI pretest or FCI posttest score. These FCI results are shown in Table 1.

Research question two investigated possible differences in conceptual understanding between Treatment and Control groups as measured by the MBT. The Cronbach's alpha value for MBT pre-test scores was 0.84, and for MBT post-test scores was 0.83 , indicating that these data were reliable. On the MBT, there was no significant difference in average pretest scores for the Treatment and Control groups $t(128)=0.791, p<.431$. However, there was a significant difference in average posttest scores on the MBT between the groups $t(126)=0.071, p<.04$. In addition, the normalized pre-to-post gain for each student was calculated by using the formula $\left(g=\frac{\text { post }- \text { pre }}{100-\text { pre }}\right)$, where pre presents pretest percent score and post represents the posttest percent score on the MBT. The average normalized gain for the Treatment group was $g=.1461$, and for the Control group was $g=.0259$. These results indicated that there was a significant difference in average normalized gain $(g)$ between Treatment and Control groups, $t(130)=5.055, p<.0001$. As hypothesized, the increase in scores resulted in a higher average normalized gain for the Treatment group. These MBT results are mentioned in Table 2.

\section{DISCUSSION}

In both treatment (DL-SCL) group and control groups, students in all lab sections completed all eleven labs in the same sequence and all study measures, but each group was exposed to a different instructional approach in the five selected labs in Week 5 to Week 10 in this Physics 1 lab. Treatment verification data confirmed fidelity of treatment by all TAs in lab sections assignment to the treatment and control groups, as well as the avoidance of multiple treatment interference. The study used the FCI and MBT instruments to measure conceptual understanding, both of which had established validity and reliability. In addition, Cronbach's alpha values for pre- 
test and post-test data sets obtained using these two measures were above 0.80 , indicating that study data were reliable. For FCI pretest and posttest scores, as well as MBT pretest, there were no statistical or obvious differences in scores for the Treatment and Control group. However, there was a significant difference on the MBT posttest between these groups.

A plausible explanation for the results regarding students' performance on MBT scores was the availability of other learning opportunities, which were only provided to students in the Treatment group. The focus of the treatment (DL-SCL lab) was to prepare students for the experiment before the lab by having them attend a group meeting and design their experimental procedure. Additionally, DL-SCL students were provided short video lectures related to the concept of the experiment were provided one week ahead of the lab. Most of these short videos explained the experimental procedure and mathematical concepts very briefly. Given this and the research design procedures intended to protect against internal validity threats, it seems reasonably safe to conclude that students who engaged in all these activities before coming to the lab better understood the experiment, and performed better overall in the lab and on the MBT when compared to students who just came to the lab with minimum preparation and performed their experiments.

Regarding indirect effects, the normalized gain on the MBT indicates that if students are prepared for their experiment before actually coming to the lab, then their ability to design an experimental investigation would improve (Etkina, Murthy, \& Zou, 2006). Students perform better on devising and testing a qualitative explanation or quantitative relationship if they have prior knowledge of the experiment (Etkina et al., 2006; Lark, 2014; Sorensen, Churukian, Maleki, \& Zollman, 2006).

These results are consistent with results from other studies that used a DL-SCL-like approach with Freshmen and Sophomores, and that used an outcome measure of conceptual understanding other than the MBT or FCI. For example, French and Cummings (2002) investigated an abridged Interactive Lecture Demonstration (ILD) protocol performed in Studio Physics 1 (Introductory Physics 1) at Rensselaer Polytechnic Institute (RPI). They found that the pre- to post-average gain, the percent correct on Newton's third law (pre-instruction $\mathrm{g}=36.2$ and postinstruction $\mathrm{g}=82.2$ with a normalized gain $\mathrm{g}=71.9$ ) as measured by Force and Motion Conceptual Evaluation (FMCE), indicated that higher levels of student understanding result from instruction students received with the studio physics curriculum. Moreover, Cummings, Marx, Thornton, and Kuhl (1999) also suggested introducing research-based techniques and activities that have clear beneficial effects. Interactive lectures and demonstrations generated a significant gain in conceptual knowledge and understanding, with remarkably less instructional time. Cooperative group problem solving resulted in similar conceptual learning gains and appeared to provide a mechanism for improved quantitative problem solving skills. Students in these cooperative group problem-solving sections had significant gains on the Force and Motion Conceptual Evaluation (FMCE) and Force Concept Inventories (FCI), and performed better on the problem-solving section of the final course exam. Cummings et al. (1999) suggested interactive lectures and demonstrations generated a significant gain in conceptual knowledge and understanding.

Most previous studies used the FCI to measure conceptual understanding, whereas this study used the MBT. However, the most of the MBT items are problem-based and require better mathematical competency and problemsolving skills than the FCI test items. Moreover, three of the 26 items on the MBT were related to impulse and momentum, which are usually difficult topics for non-physics majors to understand. Therefore, the overall gain on the MBT is usually lower than the gain on the FCI in the literature (Hake, 1998; Morote \& Pritchard, 2009). Overall, the gain in conceptual understanding $g=.146$ in this DL-SCL approach was considered to be a low gain. Most students were unable to understand difficult conceptual problems presented in the MBT. Similar results were demonstrated by McDermott (2001). McDermott mentioned that students did not develop a functional understanding of static equilibrium, despite a conceptual emphasis in instruction. A possible reason for this lack of conceptual understating might be students' inability to navigate among different mathematical representations involved.

The overall purpose of this study was to explore the value of transforming traditional content and labs using a discovery-based scientific community learning (DL-SCL) approach. The results of this study indicated that the students exposed to the DL-SCL approach scored significantly higher on measures of conceptual understanding. These results have several implications for educational practice. The broadest of these implications is that transforming traditional laboratories into discovery learning social community laboratories (DL-SCL) has the potential to increase students' content and conceptual knowledge and, by extension, their performance in laboratories and their overall interest in learning physics.

A more specific implication of this study is that these reforms can come about with small changes in a department's laboratory offerings. Most of the previously designed experiments were upgraded and only a few labs were newly designed. In addition, a department wishing to implement these laboratories may have many of the materials needed (e.g., Spark Generator, Stopwatches, apparatus for simple and physical pendulum, known masses, springs, force meter, motion sensor, photogate with Software (Logger Pro), projectile launcher, string, and 
pulleys). Most of these materials are the same as those needed for Modern Traditional Physics Laboratories or other previously used laboratories, such as Microcomputer-Based Laboratories (MBL) and RealTime Physics labs designed by Thornton and Sokoloff (1990).

Finally, on the basis of this study, I wish to suggest several ways of improving Physics- 1 Labs. First, I suggest designing a complete DL-SCL curriculum for both labs: Physics-1 Labs and Physics-2 Labs. In such a way, it would be possible to conduct the treatment for the whole semester. I suggest making the new curriculum more diversified by including the concepts from different subjects, combining mathematical, physical, and biological conceptual models into one experiment. This would help to improve students' attitude and epistemology in learning physics. Second, the full implementation of each experiment is suggested to be in two parts. Part one would include the introduction, scaffolding basic models and concepts, and improving computational skill of students, whereas part two should be more open ended, allowing majority of choices to be made by the students. Finally, group lab reports would help to adjust the extra workload as a result of the new curriculum.

\section{ACKNOWLEDGEMENTS}

The PI was working on his Ph. D. in Physics Education with support from U. S. AID. The study was conducted with the approval of PSS Department Head and Lab Director at Department of Physics, at a private engineering university in Florida. The PI has obtained support through U. S. AID to purchase the equipment and materials needed to conduct both pilot and full study.

\section{REFERENCES}

Beichner, R. J. (1996). The impact of video motion analysis on kinematics graph interpretation skills. American Journal of Physics, 64(10), 1272-1277. https:/ / doi.org/10.1119/1.18390

Beichner, R. J., Saul, J. M., Abbott, D. S., Morse, J. J., Deardorff, D., Allain, R. J., Bonham, S. W., Dancy, M. H., \& Risley, J. S. (2007). The student-centered activities for large enrollment undergraduate programs (SCALEUP) project. Research-Based Reform of University Physics, 1(1), 2-39.

Bodner, G. M., Hunter, W. J., \& Lamba, R. S. (1998). What happens when discovery laboratories are integrated into the curriculum at a large research university? The Chemical Educator, 3(3), 1-21. https:/ / doi.org/10.1007/s00897980214a

Cummings, K., Marx, J., Thornton, R., \& Kuhl, D. (1999). Evaluating innovation in studio physics. American Journal of Physics, 67(1), 38-44. https:// doi.org/10.1119/1.19078

Docktor, J. L., \& Mestre, J. P. (2014). Synthesis of discipline-based education research in physics. Physical Review Special Topics-Physics Education Research, 10(2), 1-58. https:/ / doi.org/10.1103/PhysRevSTPER.10.020119

Dori, Y. J., \& Belcher, J. (2005). How does technology-enabled active learning affect undergraduate students' understanding of electromagnetism concepts? The Journal of the Learning Sciences, 14(2), 243-279. https://doi.org/10.1207/s15327809j1s1402_3

Escalada, L. T. (1995). An investigation on the effects of using interactive digital video in a physics classroom on student learning and attitudes. (Doctoral dissertation, Kansas State University). Retrieved from https:// web.phys.ksu.edu/dissertations/escaladaMS.pdf

Etkina, E. \& Van Heuvelen, A. (2007). Investigative science learning environment-a science process approach to learning physics. Research-Based Reform of University Physics 1(1), 1-48. Retrieved from http://www.compadre.org/PER/per_reviews/media/volume1/ISLE-2007.pdf

Etkina, E., Karelina, A., Ruibal-Villasenor, M., Rosengrant, D., Jordan, R., \& Hmelo-Silver, C. E. (2010). Design and reflection help students develop scientific abilities: Learning in introductory physics laboratories. The Journal of the Learning Sciences, 19(1), 54-98. https:/ / doi.org/10.1080/10508400903452876

Etkina, E., Murthy, S., \& Zou, X. (2006). Using introductory labs to engage students in experimental design. American Journal of Physics, 74(11), 979-986. https:/ / doi.org/10.1119/1.2238885

French, T., \& Cummings, K. (2002, Aug). Effectiveness of abridged interactive lecture demonstrations. Paper presented at the Paper presented at Physics Education Research Conference 2002, Boise, Idaho. https:// doi.org/10.1119/perc.2002.pr.003

Gresser, P. W. (2006). A study of social interaction and teamwork in reformed physics laboratories. (Doctoral dissertation, University of Maryland). Retrieved from http://drum.lib.umd.edu/bitstream/handle/1903/3362/umiumd-3171.pdf?sequence=1 
Hake, R. R. (1998). Interactive-engagement versus traditional methods: A six-thousand-student survey of mechanics test data for introductory physics courses. American Journal of Physics, 66(1), 64-74. https:// doi.org/10.1119/1.18809

Hestenes, D., \& Wells, M. (1992). A mechanics baseline test. The Physics Teacher, 30(3), 159-166. https:/ / doi.org/10.1119/1.2343498

Hestenes, D., Wells, M., \& Swackhamer, G. (1992). Force concept inventory. The Physics Teacher, 30(3), $141-158$. https:// doi.org/10.1119/1.2343497

Ivie, R., \& Ray, K. N. (2005, Feb). Women in physics and astronomy, American Institute of Physics (AIP) Statistical Research Center. (AIP online published report no R-430.02). https:/ / doi.org/10.1063/1.2128268

Kung, R. L. (2005). Teaching the concepts of measurement: An example of a concept-based laboratory course. American Journal of Physics, 73(8), 771-777. https:// doi.org/10.1119/1.1881253

Lark, A. (2014). Implementation of scientific community laboratories and their effect on student conceptual learning, attitudes, and understanding of uncertainty. (Doctoral dissertation, The University of Toledo). Retrieved from http:/ / utdr.utoledo.edu/cgi/viewcontent.cgi?article=2616\&context=theses-dissertations

Lippmann, R. F. (2003). Students' understanding of measurement and uncertainty in the physics laboratory: Social construction, underlying concepts, and quantitative analysis. (Doctoral dissertation, University of Maryland). Retrieved from http://www.physics.umd.edu/perg/dissertations/Lippmann/Body.pdf

McCullough, L. E. (2000). The effect of introducing computers into an introductory physics problem-solving laboratory. (Doctoral dissertation, University of Minnesota). Available from ProQuest Dissertations and Theses database. (UMI No. 9972998)

McDermott, L. C. (2001). Oersted medal lecture 2001: Physics Education Research - the key to student learning. American Journal of Physics, 69(11), 1127-1137. https:/ / doi.org/10.1119/1.1389280

Morote, E. S., \& Pritchard, D. E. (2009). What course element correlate with improvement on test in introductory Newtonian mechanics. American Journal of Physics, 77(8), 746-753. https://doi.org/10.1119/1.3139533

National Research Council (NRC). (2013). Adapting to a changing world: Challenges and opportunities in undergraduate physics education. Washington, DC: The National Academies Press. Retrieved from http:/ / www.nap.edu/catalog/18312/adapting-to-a-changing-world-challenges-and-opportunities-inundergraduate

Redish, E. F. (2003). Teaching physics with the physics suite CD. New York: Wiley.

Saul, J. M., \& Beichner, R. (2001, July). An activity-based curriculum for large introductory physics classes: The SCALEUP project. Paper presented at Physics Education Research Conference 2001, Rochester, NY. https://doi.org/10.1119/perc.2001.pr.016

Seymour, E., \& Hewitt, N. M. (1997). Talking about leaving: Why undergraduates leave the sciences. Boulder, CO: Westview Press.

Sokoloff, D. R. (2012). RealTime Physics Active Learning Laboratories, Module 4: Light and optics (3rd Ed.). Hoboken, NJ: John Wiley \& Sons.

Sokoloff, D. R., Laws, P. W., \& Thornton, R. K. (2007). RealTime Physics: active learning labs transforming the introductory laboratory. European Journal of Physics, 28(3), 83-94. https://doi.org/10.1088/01430807/28/3/S08

Sokoloff, D. R., Thornton, R. K., \& Laws, P. W. (2011). RealTime Physics Active Learning Laboratories, Module 1: Mechanics. Hoboken, New Jersey: John Wiley \& Sons.

Sorensen, C., Churukian, A., Maleki, S., \& Zollman, D. (2006). The New studio format for instruction of introductory physics. American Journal of Physics, 74(12), 1077-1082. https:/ / doi.org/10.1119/1.2358999

Thornton, R. K., \& Sokoloff, D. R. (1990). Learning motion concepts using real-time microcomputer-based laboratory tools. American Journal of Physics, 58(9), 858-867. https:/ / doi.org/10.1119/1.16350

Thornton, R. K., \& Sokoloff, D. R. (1997, March). Realtime physics: active learning laboratory. Paper presented at the The Changing Role of Physics Departments in Modern Universities, Vol. 39, (pp. 1101-1118). College Park, MD: AIP Publisher. https:/ / doi.org/10.1063/1.53111

Upton, B. M. (2010). Assessing the effectiveness of studio physics at Georgia State University. (Thesis, Georgia State University). Retrieved from http:/ / scholarworks.gsu.edu/cgi/viewcontent.cgi?article=1009\&context=phy _astr_theses

\section{http://www.ejmste.com}

